\title{
Evaluation of different therapeutic Carnoy's formulations on hard human tissues: A Raman microspectroscopy, microhardness, and scanning electron microscopy study
}

\author{
Francisco Samuel Rodrigues Carvalho ${ }^{\text {a, b, * }}$, Victor Pinheiro Feitosa c, \\ Paulo Goberlânio de Barros Silva ${ }^{\mathrm{d}}$, Eduardo Costa Studart Soares ${ }^{\mathrm{e}}$, \\ Thyciana Rodrigues Ribeiro ${ }^{\mathrm{f}}$, Cristiane Sá Roriz Fonteles ${ }^{\mathrm{f}}$, Fábio Wildson Gurgel Costa ${ }^{\mathrm{g}}$ \\ a Division of Oral and Maxillofacial Surgery, Federal University of Ceará, Fortaleza, Brazil \\ b Division of Oral and Maxillofacial Morphology and Oral and Maxillofacial Surgery, UNIFOR, Fortaleza, Brazil \\ c Paulo Picanço School of Dentistry, Fortaleza, Ceará, Brazil \\ d Unichristus University Center, Fortaleza, Ceará, Brazil \\ e Division of Oral and Maxillofacial Surgery, Walter Cantídio University Hospital, Federal University of Ceará, Fortaleza, Brazil \\ f School of Dentistry, Federal University of Ceará, Ceará, Fortaleza, Brazil \\ ${ }^{\mathrm{g}}$ Division of Oral Radiology, Walter Cantídio University Hospital, Federal University of Ceará, Fortaleza, Brazil
}

\section{A R T I C L E I N F O}

\section{Article history:}

Paper received 29 November 2017

Accepted 14 February 2018

Available online 21 February 2018

\section{Keywords:}

Carnoy's solution

Hard tissues

Treatment

Raman microspectroscopy

In vitro study

\begin{abstract}
A B S T R A C T
Purpose: To evaluate different therapeutic Carnoy's solution formulations on hard human tissues. Materials and methods: An in vitro study was performed with human teeth $(\mathrm{n}=36)$ and bone fragments $(\mathrm{n}=18$ ), randomly divided into two experimental groups (Group I = Carnoy solution with chloroform; Group II = Carnoy solution without chloroform) and a control group (saline solution). The groups were subdivided into pre-conditioning, post-conditioning, and post-conditioning with saline washing. Raman microspectroscopy, Knoop microhardness test, and scanning electron microscopy with energy dispersive $\mathrm{X}$-ray spectroscopy were used.

Results: There was demineralization of dental structures regarding mineral/matrix and carbonate/phosphate ratios (GI versus GII, $\mathrm{p}<0.05$ ). The presence of chloroform resulted in a statistically significant reduction of the teeth surface microhardness $(\mathrm{p}=0.036)$, but not exceeding $0.01 \mu \mathrm{m}$. Both GI and GII showed significant structural changes by using scanning electron microscopy with energy dispersive X-ray spectroscopy. Conclusion: Carnoy's solution altered the organic and inorganic matrix of the human calcified specimens analyzed in vitro, and its effect was more pronounced when chloroform was present.
\end{abstract}

() 2018 Published by Elsevier Ltd on behalf of European Association for Cranio-Maxillo-Facial Surgery.

\section{Introduction}

Benign lesions (odontogenic and non-odontogenic), but locally aggressive and with a high percentage of recurrence, may occur within the maxillofacial region. (Abou Neel et al., 2016) Conservative treatment of these jaw lesions can lead to high recurrence rates; however, a radical approach usually is followed by severe functional and aesthetic impairments (Costa et al., 2010; Pogrel, 2015). Adjunct therapies allied to surgical treatments, such as the use of Carnoy's solution or liquid nitrogen as a cryosurgical agent, have been widely used since the 1980s, aiming to improve clinical outcomes (Costa et al., 2011).

\footnotetext{
* Corresponding author. Rua Monsenhor Furtado, s/n. Rodolfo Teófilo, Fortaleza, CEP: 60.430-350, Ceará, Brazil.

E-mail address: samuelcarvalho@unifor.br (F.S.R. Carvalho).
}

Voorsmit, Stoelinga and van Haelst in 1981 (Voorsmit et al., 1981) were the first investigators that used Carnoy's solution in intraosseous-related jaw lesions, recommending the use of this cauterizing agent in the treatment of odontogenic keratocysts, as this lesion shows important infiltration patterns and high rates of recurrence (Voorsmit et al., 1981). Since its first use in the field of surgical interventions, Carnoy's solution has also been reported in the adjunct treatment of other pathologies such as glandular odontogenic cyst (Cano et al., 2012), ossifying fibroma of the jaws (Gurol et al., 2001; Rajeshkumar et al., 2013), and ameloblastomas (Lee et al., 2004).

Based on previously published studies (Costa et al., 2010; Voorsmit et al., 1981; Hellstein et al., 2007; Cutler and Zollinger, 1933), Voorsmit established a clinical protocol for applying 
Carnoy's solution over a period of 5 min on the bony defect, which promoted necrosis of approximately $1.5 \mathrm{~mm}$ in depth (Voorsmit, 1985). Initially, the Carnoy's solution consisted of $9 \mathrm{ml}$ of $95 \%$ ethanol, $3 \mathrm{ml}$ of glacial acetic acid, and $1 \mathrm{~g}$ of ferric chloride (Hellstein et al., 2007). Subsequently, there were two important changes in its formulation: (1) presence of $6 \mathrm{ml}$ of absolute alcohol instead of ethanol; and (2) addition of chloroform (Cutler and Zollinger, 1933). However, the addition of chloroform has been discussed in the literature (Hellstein et al., 2007; Dashow et al., 2013). Since 2000, the US Food and Drug Administration has prohibited its use in cosmetic products because of its carcinogenicity as observed in animal studies and a probable risk to human health (US Food and Drug Administration, 1992).

The evidence of bony penetrability and therapeutic effect have been demonstrated in experimental (Voorsmit et al., 1981) and clinical studies (Dashow et al., 2013), respectively. In some clinical situations, there is a possibility of this chemical agent covering teeth root surfaces after its application in surgical cavities closely adjacent to vital teeth. However, there is a lack of knowledge regarding the in vitro effects of Carnoy's solution, with or without chloroform, on the tooth root surface. In comparison with cryotherapy, which has yielded important data in the study by Pollan et al. (1974), which described the effects of liquid nitrogen on root teeth obtained from dogs, there is no in vitro or in vivo similar investigations involving Carnoy's solution to date.

In addition to uncertain effects of Carnoy's solution when in contact with dentin from root surfaces, possible mechanisms explaining the clinical outcomes after its use in human bone tissue remain unclear. In the field of Carnoy's solution applied in oral and maxillofacial surgery, it could be beneficial if chemical analysis was performed. For this purpose, there are specific methodologies such as Raman microspectroscopy.

In 1928, the Indian physicist Sir Chandrasekhara Venkata Raman observed and analyzed the phenomenon of light inelastic scattering through matter using a microspectroscopy technique called the Raman effect (Kann et al., 2015). Raman microspectroscopy is recognized as a valuable analytical technique for measuring the chemical composition of complex biological samples, such as biofluids, cells, and tissues. In addition, it has been considered as a modern molecular fingerprint of different substrates, providing quantitative information regarding its chemical composition (Kong et al., 2015). This methodology is considered to be a noninvasive, chemically selective modality that has been reported in oral surgery-related scientific publications (Zizzari et al., 2016; Carvalho et al., 2017; Owosho et al., 2014).

We have recently conducted physicochemical and rheological characterizations of different Carnoy's solutions (Carvalho et al., 2017); however, in vitro effects on mineralized oral tissues were not reported. Thus, the objective of the present study was to perform a novel investigation of possible physico-chemical alterations of different calcified human substrates (teeth and bone tissue) that have undergone different Carnoy's solution protocols through Raman microspectroscopy, the Knoop microhardness test, and scanning electron microscopy approaches. To date, there are no published studies that have conducted a similar investigation with distinct Carnoy's solution formulations.

\section{Materials and methods}

\subsection{Study design and samples}

An in vitro study evaluating two Carnoy's solution formulations was performed after its approval by the Ethics Committee on Human Research at the Federal University of Ceará, Brazil (protocol \#1.610.791). The samples consisted of 36 lower third molars and 18 fresh jaw bone tissue fragments obtained from the Oral and Maxillofacial Surgery Unit at the Walter Cantídio University Hospital (Fortaleza, Ceará, Brazil). The samples were obtained from volunteers who signed an appropriate written informed consent.

All teeth were obtained from healthy patients (American Society of Anesthesiologists classification I) who underwent surgical removal of lower third molars, and the teeth were immediately stored in $0.9 \%$ physiological solution at $4{ }^{\circ} \mathrm{C}$ for a maximum period of 7 days until the experimental protocol. Bone specimens were stored in $0.9 \%$ physiological solution and subjected to the experiments on the same day that they were obtained. We used $0.9 \%$ physiological solution aiming to preserve the characteristics of cementum (Hawkins et al., 1997) and bone structure (Suvorova et al., 2007). In addition, no root surface treatment was performed, such as scaling or conditioning with acidic solutions, aiming to maintain the structural integrity of the cementum and a possible maintenance of remaining periodontal fibers. All teeth were equally allocated between each experimental group and its subgroup (Fig. 1).

The bone fragments were obtained from a single healthy patient (American Society of Anesthesiologists classification I) who underwent orthognathic surgery, and they were appropriately stored immediately after the surgical procedure. These fragments were previously sectioned with a metallographic cutter (Buehler-Model ISOMETTM LS; Lake Bluff, IL, USA) using a diamond disk under irrigation with physiological saline solution, and sectioned to obtain specimens with the following dimensions: $0.4 \mathrm{~cm}$ in width, $1 \mathrm{~cm}$ in height, and 0.5 in cm thickness. Subsequently, these blocks were equally allocated between each experimental group and its subgroup (Fig. 1). The protocol experiments in bone specimens were conducted on the same day as they were obtained.

\subsection{Inclusion criteria}

To be included in the present study, all teeth should be healthy, as well as their removal would have to be done with the use of forceps or elevators in order to maintain the integrity of the root tooth surface. In addition, it was decided that the teeth would need to present at least two-thirds of root formation aiming to guarantee a representative area for Raman microspectroscopy analysis.

The bone fragments would need to be originated from mandibular orthognathic surgery, the planning for which included the need for its removal.

\subsection{Exclusion criteria}

Exclusion criteria consisted of dental decay, teeth presenting with dental calculus root formation, teeth that previously received periodontal treatment, root fractures, and root teeth with superficial macroscopic alterations, as well as macroscopically altered bone fragments revealing attached pathological tissue or superficial morphological alterations probably during their removal.

\subsection{Preparation of Carnoy's solutions}

The Carnoy's solutions used in this investigation were prepared by the same trained pharmaceutical specialist as described in our previous investigation (Carvalho et al., 2017). A solution was formulated using $6 \mathrm{ml}$ of absolute ethanol, $3 \mathrm{ml}$ of chloroform, $1 \mathrm{ml}$ of acetic acid, and $1 \mathrm{~g}$ of ferric chloride hexahydrate $\left(\mathrm{FeCl}_{3} \cdot 6 \mathrm{H}_{2} \mathrm{O}\right)$ in order to obtain approximately $10 \mathrm{ml}$ of a final solution (Voorsmit et al., 1981; Cutler and Zollinger, 1933). The experimental solution without chloroform was obtained by using $3 \mathrm{ml}$ of chloroform instead of $3 \mathrm{ml}$ of absolute ethanol as described in other studies (Hellstein et al., 2007; Dashow et al., 2013; Ecker et al., 2016). Both Carnoy's solutions were immediately stored in amber glass bottles 


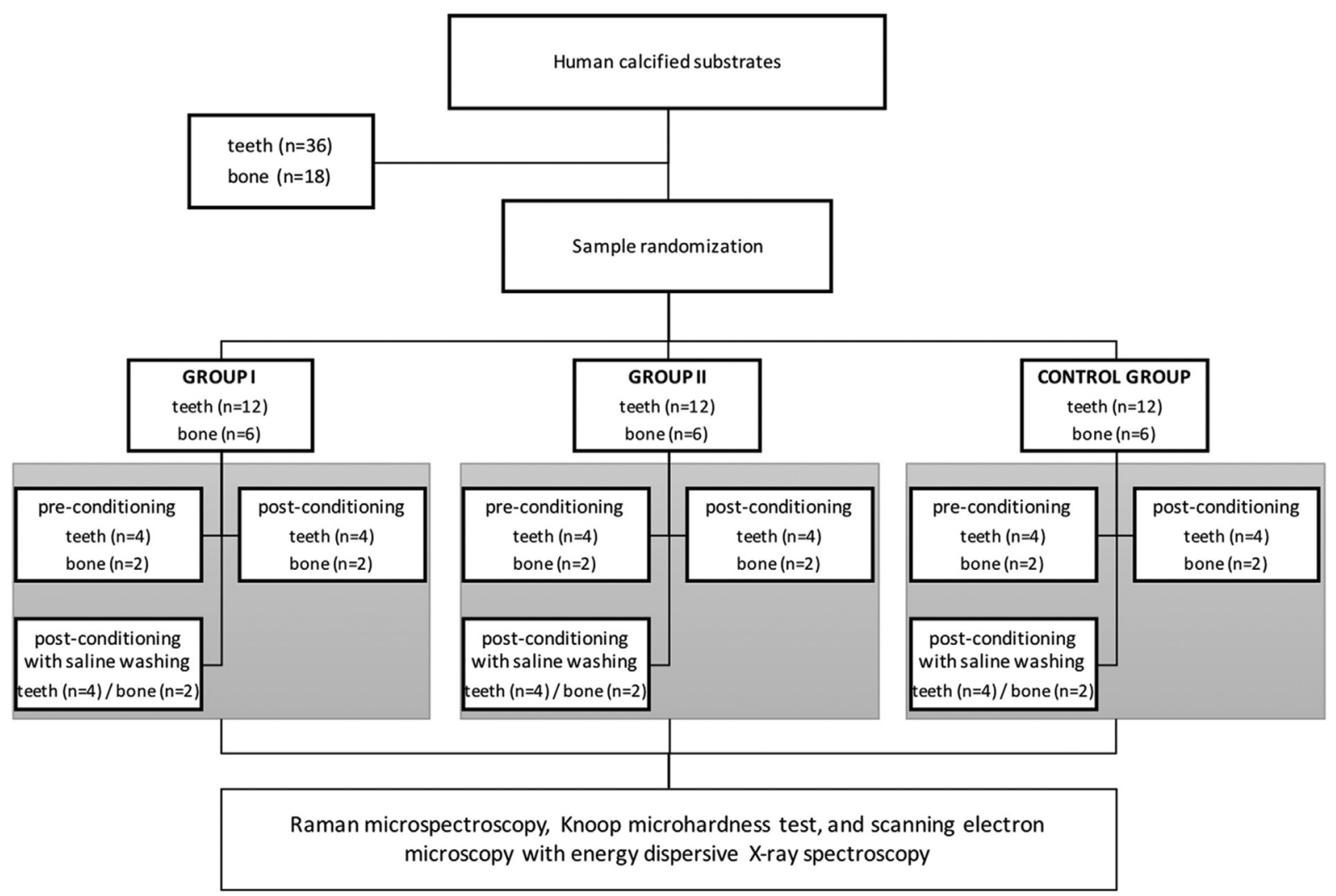

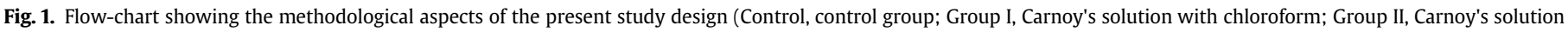
without chloroform).

with a plastic cap and maintained in a cool, light-free room at room temperature until the beginning of the experiments. In addition, all solutions were handled and used on the same day of preparation, and were appropriately discarded soon after finishing the experiments.

\subsection{Experimental protocol}

The total of specimens used in the present study was required aiming to perform triplicate data acquisition. A collaborator who was unaware of the research protocol and who did not participate in any laboratory phases of the present investigation numbered and randomly allocated all specimens (Randbetween function, Microsoft Excel ${ }^{\circledR}$; Microsoft Corp., Redmond, WA, USA) to the studied groups. There were three main groups, and each group was further divided into two subgroups according to the experimental protocol. The main groups were classified as: Carnoy's solution with chloroform (group I), Carnoy's solution without chloroform (group II), and saline solution (control; group III). In each group, specimens were separated into those that received or did not receive washing with $0.9 \%$ sodium chloride $(0.9 \%$ saline solution; Fresenius Kabi Brazil Ltda, Barueri, SP, Brazil) after using Carnoy's solution.

The human specimens were first immersed during a 5-min period in a glass recipient containing $100 \mathrm{ml}$ of the tested solution according to its group. After that, they were removed using plastic tweezers. If the subgroup did not include washing with a physiological solution, the specimens were packed in individual plastic containers at room temperature. However, if the subgroup involved irrigation with a physiological solution prior to storage, the substrates had their surfaces irrigated with saline solution $0.9 \%$ during a period of 5 min (Fig. 1). The introduction of a subgroup with saline washing was to simulate, in an in vitro environment, the procedure that is usually performed in surgical protocols using Carnoy's solutions.

All specimens were sectioned in order to obtain 3 sagittal sections (Fig. 1). These were analyzed by Raman microspectroscopy, Knoop microhardness test, and scanning electron microscopy/ energy-dispersive X-ray spectroscopy. A previously trained investigator who was unaware of the studied groups/subgroups performed all analyzes, aiming to provide a blinded study design. In addition, the statistical analysis was initially carried out with groups coded with the letter " $A$ " representing the Carnoy's solution group with chloroform, "B" representing the Carnoy's solution group without chloroform, and " $\mathrm{C}$ " representing the control group. The envelope decoding this information was accessed only after the statistical analysis had been concluded.

\subsection{Raman microspectroscopy}

Initially, all specimens were evaluated by Raman microspectrometry (Xplora, Horiba, Paris, France). The Raman spectra were first acquired in LabSpec 6 software (Horiba Jobin Yvon Inc, Edison, NJ, USA) and then manipulated in OriginPro 9.0 software (OriginLab Co., Northampton, MA, USA). They were processed with baseline correction, smoothing by the polynomial method (SavitzkGolay) and peaks position/intensity identification by Gaussian and Lorentzian methods to ensure characterization and deconvolution of graphs (Nouri et al., 2015). The spatial distribution of the organic and inorganic components were determined by the relative intensities of peaks obtained in a Raman microspectrophotometer. An argon laser with $638-\mathrm{nm}$ wavelength and 3.2-mW power were used along with $10 \mathrm{x}$ and $100 \mathrm{x}$ magnification lens (Olympus American Inc., London, UK) to provide the focus. 
As a standardized procedure adopted in the present study, teeth were submitted to evaluation in three root regions: apical, cervical, and a midpoint between the apical and cervical regions (Fig. 2A). Bone specimens were evaluated in three focal regions (Fig. 2B): two points located $2.0 \mathrm{~mm}$ from the lateral aspects of the specimens, and a midpoint located between these points. Raman spectra were obtained at baseline ("pre-conditioning"), after conditioning with Carnoy's solutions ("post-conditioning"), and after postconditioning with or without saline washing.

Raman spectra were attained in the range between 400 and $4000 \mathrm{~cm}^{-1}$ with 3 accumulations and $10 \mathrm{~s}^{\prime}$ acquisition time per analyzed region. The analyzed Raman spectra variables were as follows: (1) mineral to matrix ratio calculated by intensity of phosphate $v 1$ band $\left(\sim 958 \mathrm{~cm}^{-1}\right)$ divided by the combined intensities of proline and hydroxyproline bands $\left(854+871 \mathrm{~cm}^{-1}\right)$; and (2) carbonate to phosphate ratio measured by the intensity ratio of the carbonate band $\left(\sim 1070 \mathrm{~cm}^{-1}\right)$ to the phosphate $v 1$ band $\left(\sim 958 \mathrm{~cm}^{-1}\right)$ (Gong et al., 2013).

The present study evaluated the existing relations between band intensities due to the variability of data acquisition in Raman microspectroscopy. It includes the likelihood of a photon causing a Raman scattering effect, as well as the specimen orientation, volume of laser-excited material, light absorption, cosmic radiation, and fluorescence. Thus, this measure would act to reduce interferences from external agents, as recommended in the published literature (Gong et al., 2013; Butler et al., 2016).

\subsection{Knoop microhardness test}

All teeth were mesiodistally sectioned into equal cross-sectional parts using a water-cooled low-speed Isomet diamond saw (Buehler Ltd., Lake Bluff, IL, USA). The resulting teeth sections were positioned on self-cure acrylic-filled cylindrical molds, with the sectioned surface facing outward and then metallographically polished using a series of 400,500 , and 600 silicon carbide abrasive grit papers. The specimens were finely polished with a water-based diamond paste of 1 to $0.25 \mu \mathrm{m}$ (Buehler, Lake Bluff, IL, USA) at low speed over a 180-s interval to provide a flat surface, which was confirmed at x40 magnification. This protocol was adopted because microhardness requires polished dental surfaces aiming to allow an adequated visualization of the indentations (Albuquerque et al., 2016).

Knoop microhardness was evaluated using a microhardness tester (Shimadzu HMV-2000, Shimadzu Corporation, Kyoto, Japan). Settings for load and penetration were $25 \mathrm{~g}$ and $15 \mathrm{~s}$, respectively.
Knoop penetrations were made on the acrylic surface of each sample (apical, cervical, and middle root regions adopted in the present study) at depths of $0.01,0.11$, and $0.21 \mu \mathrm{m}$ (Fig. 2A). Three measurements were performed for each distance, and a mean value was calculated.

\subsection{Scanning electron microscopy/Energy dispersive spectroscopy}

After finishing the previously described tests, the specimens were mounted onto stubs with double-faced conductive adhesive tape, metalized with gold powder (Suvorova et al., 2007) (Quorum Metallizer QT150ES, Quorum Technologies, Laughton, UK), vacuumized, and then analyzed using a scanning electron microscopy (SEM inspect-50, FEI, Hillsboro, OR, USA). This was used in conjunction with an energy-dispersive X-ray spectroscopy detector (Oxford Instruments, Abingdon, Oxfordshire, UK) installed in the vacuum chamber of the scanning electron microscope. The surface images were captured through a Philips XL30 microscope, and all analyses were performed using the manufacturer's software (AztecEnergy, Oxford Instruments, Abingdon, Oxfordshire, UK). This protocol aimed to evaluate possible surface changes and composition of the studied specimens.

\subsection{Statistical analysis}

Raman microspectroscopy data are presented as mean \pm standard error of the mean. The difference between groups was evaluated using one-way analysis of variance followed by the Bonferroni posttest. Data from the Knoop hardness test were analyzed using the Student t test. All analysis were performed using the GraphPad Prism 5.0 software, and the significance level for all variables was fixed at $5 \%$. In addition, scanning electron microscopy data were analyzed by observation of qualitative structural alterations on the evaluated surfaces and quantifying the proportion of sample components.

\section{Results}

\subsection{Raman microspectroscopy}

The analysis of isolated bands and peaks provided significant changes in phosphate v1 $\left(\sim 960 \mathrm{~cm}^{-1}\right)$ and carbonate $\left(\sim 1070 \mathrm{~cm}^{-1}\right)$ bands (Fig. 3). This finding was noticeable because of the loss of the phosphate v1 band after conditioning with both Carnoy's solutions on the dental substrate (Fig. 3A and B), as well as the loss of the
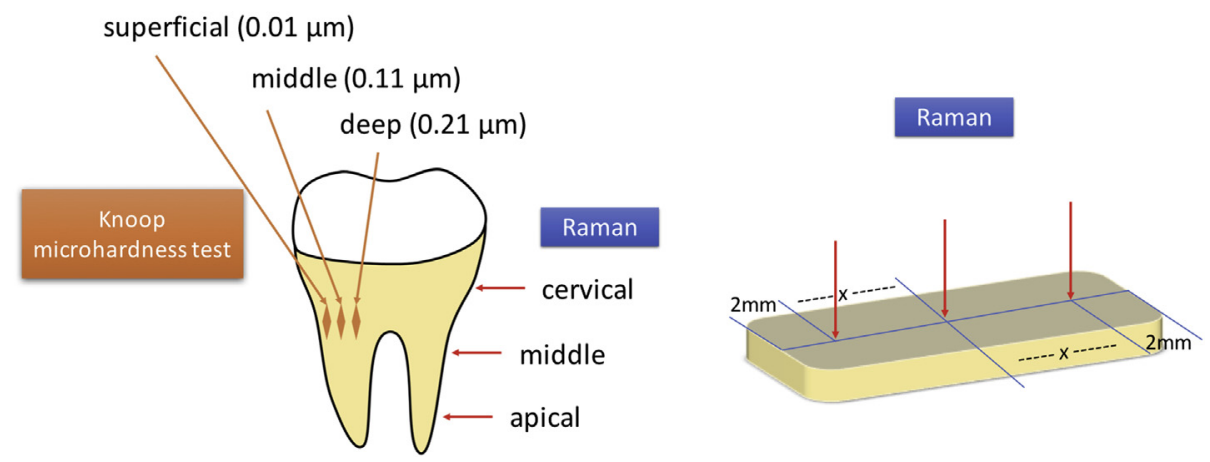

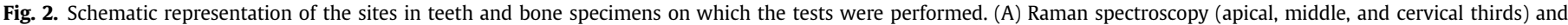

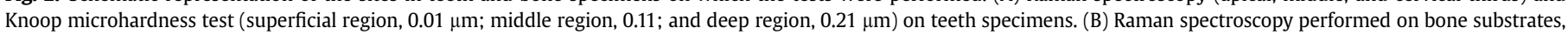
registered at $2 \mathrm{~mm}$ from the margins and $1 \mathrm{~mm}$ at the midpoint between them. 
peak after washing with saline solution in the substrate bone treated with Carnoy's solution without chloroform (Fig. 3D). After analyzing the isolated bands, the values obtained by the Raman parameters of the human substrates conditioned with Carnoy's solution with chloroform and that without chloroform (Tables 1 and 2) were evaluated. The mineral matrix/organic matrix and carbonate/phosphate (Fig. 4) were evaluated in the cementum and bone surface (Fig. 5) of the specimens.

In the root teeth surface, a reduced mineral matrix/organic matrix ratio was observed when both studied Carnoy's solutions were used (Fig. 4A). Considering this parameter in relation to group II, a statistically significant difference $(\mathrm{p}=0.025)$ was observed between preconditioning, post-conditioning, and post-conditioning followed by saline washing. In this group, a statistically significant difference was observed between pre-conditioning versus post-conditioning with saline washing $(\mathrm{p}=0.003)$. In the group in which Carnoy's solution was formulated with chloroform (group I), a statistically significant difference was observed between pre-conditioning versus post-conditioning ( $\mathrm{p}=0.004$ ), as well as pre-conditioning versus post-conditioning with saline washing $(\mathrm{p}=0.001)$.

There was an increase of cementum carbonate/phosphate ratio in Carnoy's solution either with or without chloroform (Fig. 4B). In group I, there was a statistically significant difference for this parameter regarding pre-conditioning versus post-conditioning $(\mathrm{p}=0.036)$, and pre-conditioning versus post-conditioning with saline washing $(\mathrm{p}=0.001)$. In group II, a statistically significant difference ( $\mathrm{p}=0.004)$ was observed between pre-conditioning, post-conditioning, and post-conditioning with saline washing. In this experimental group, a statistically significant difference was observed between pre-conditioning versus post-conditioning with saline washing $(\mathrm{p}=0.001)$.

\subsection{Knoop microhardness}

There was a decrease in Knoop microhardness between pre- and post-conditioning values when the test was performed at a distance of $0.01 \mu \mathrm{m}$. Table 3 shows differences among group I (pre-conditioning, $38.48 \pm 4.411$; post-conditioning, $24.06 \pm 1.413$ ), group II (pre-conditioning, $38.48 \pm 4.411$; post-conditioning, $32.96 \pm 2.733$ ), and the control group (pre-conditioning, $34.08 \pm 5.994$; postconditioning, $40.25 \pm 9.369$ ). There was a statistically significant difference ( $\mathrm{p}=0.036$ ) in group I (Fig. 6).

\subsection{Scanning electron microscopy/Energy-dispersive spectroscopy}

It has been known that calcium (Ca) content in normal cementum is usually higher than phosphorus (P) amount (Fig. 7A) (Almehdi et al., 2013). However, group I (Fig. 7C) showed Ca-P ratio reduced and inverted, reduction of the organic component (carbon - C), and an increase in the concentration of iron ions (Fe). In this group, post-conditioning with saline washing rendered a normal $\mathrm{Ca}-\mathrm{P}$ ratio but inverted, reestablishment of the organic component (C), and reduction of the concentration of Fe ions (Fig. 7E). Similarly, group II showed na inversion of the $\mathrm{Ca}-\mathrm{P}$ ratio and organic component $(\mathrm{C})$ preservation; however, there was an increase in the concentration of $\mathrm{Fe}$ ions (Fig. 8I). Post-conditioning with saline washing rendered a normal proportion between $\mathrm{Ca}$ and $\mathrm{P}$ contents, decrease in the organic component (C), and reduced concentration of Fe ions (Fig. 7I). In addition, smear-layer was observed after conditioning with both Carnoy solutions (Fig. 7D and H), but group II showed a reduction in its electrodensity (Fig. 7H). Postconditioning with saline washing did not show the presence of smear-layer either in group I or II (Fig. 7F and L); however, a more
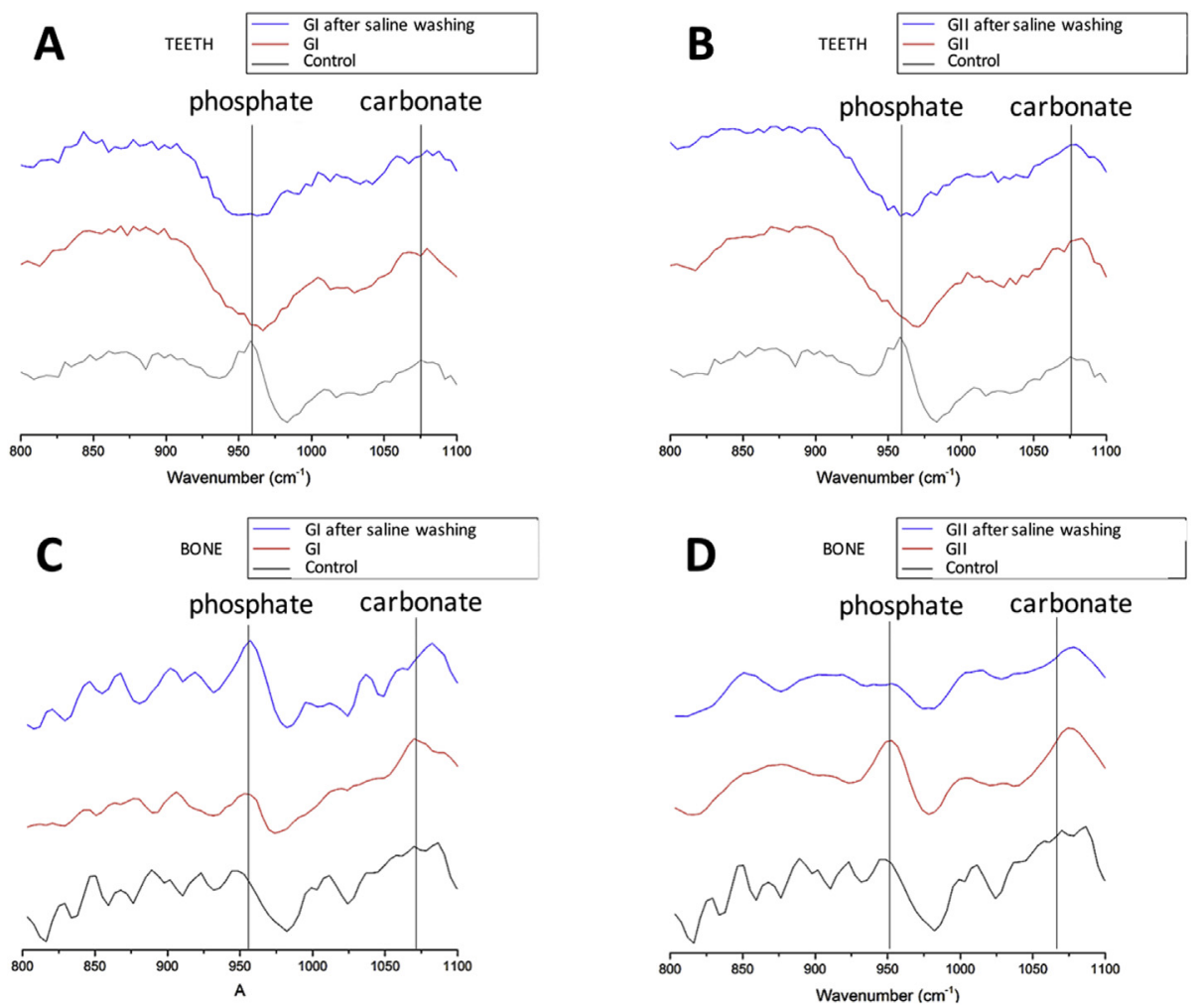

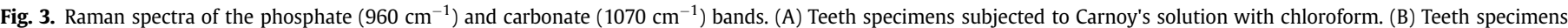

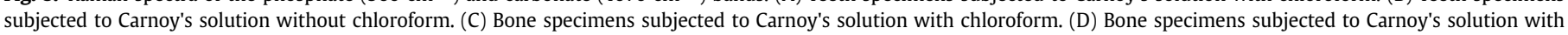
chloroform. GI, group I. GII, group II. 
Table 1

Raman spectra data according to mineral/matrix and carbonate/phosphate ratios on teeth specimens.

\begin{tabular}{|c|c|c|c|c|c|c|c|c|}
\hline & Control PRE & Control POST & Group I PRE & Group I POST & $\begin{array}{l}\text { Group I } \\
\text { POST + washing }\end{array}$ & Group II PRE & Group II POST & $\begin{array}{l}\text { Group II } \\
\text { POST + washing }\end{array}$ \\
\hline \multicolumn{9}{|l|}{ Mineral/Matrix ratio } \\
\hline Mean & 0.1911 & 0.06497 & 0.2153 & 0.1289 & 0.04592 & 0.2102 & 0.04253 & 0.0814 \\
\hline $\begin{array}{l}\text { Standard error of the mean } \\
\text { Carbonate/Phosphate ratio }\end{array}$ & 0.04581 & 0.03064 & 0.05293 & 0.06336 & 0.02739 & 0.04383 & 0.003497 & 0.03088 \\
\hline Mean & 7.991 & 10.2 & 3.661 & 9.735 & 13.85 & 3.49 & 8.088 & 10.92 \\
\hline Standard error of the mean & 8.692 & 13.37 & 3.881 & 10.79 & 13.02 & 4.335 & 8.976 & 7.917 \\
\hline
\end{tabular}

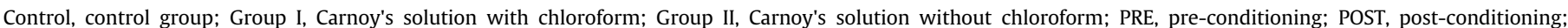
POST + washing, post-conditioning followed by saline washing.

Table 2

Raman spectra data according to mineral/matrix, carbonate/phosphate ratios on bone specimens.

\begin{tabular}{|c|c|c|c|c|c|c|c|c|}
\hline & Control PRE & Control POST & Group I PRE & Group I POST & $\begin{array}{l}\text { Group I } \\
\text { POST + washing }\end{array}$ & Group II PRE & Group II POST & $\begin{array}{l}\text { Group II } \\
\text { POST + washing }\end{array}$ \\
\hline \multicolumn{9}{|l|}{ Mineral/Matrix ratio } \\
\hline Mean & 0.393 & 0.5575 & 0.2153 & 0.6576 & 0.4934 & 0.4954 & 0.4354 & 0.6617 \\
\hline $\begin{array}{l}\text { Standard error of the mean } \\
\text { Carbonate/Phosphate ratio }\end{array}$ & 0.1312 & 0.1078 & 0.05293 & 0.1019 & 0.005851 & 0.3636 & 0.1188 & 0.05361 \\
\hline Mean & 2.945 & 0.5575 & 3.661 & 1.176 & 0.4934 & 0.4954 & 1.729 & 0.6617 \\
\hline Standard error of the mean & 1.567 & 0.1078 & 3.881 & 0.214 & 0.005851 & 0.3636 & 0.6878 & 0.05361 \\
\hline
\end{tabular}

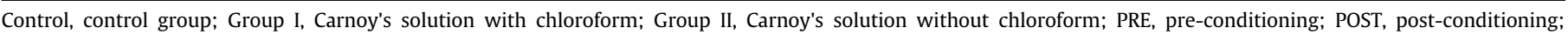
POST + washing, post-conditioning followed by saline washing.
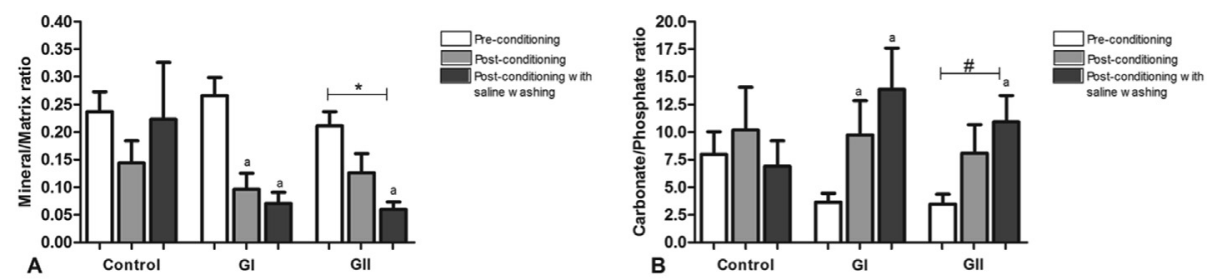

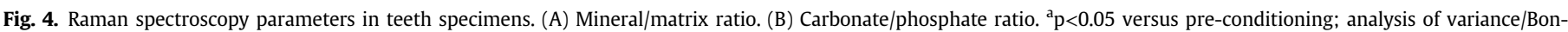
ferroni test. GI, group I. GII, group II. * $\mathrm{p}=0.025$; $\# \mathrm{p}=0.004$.
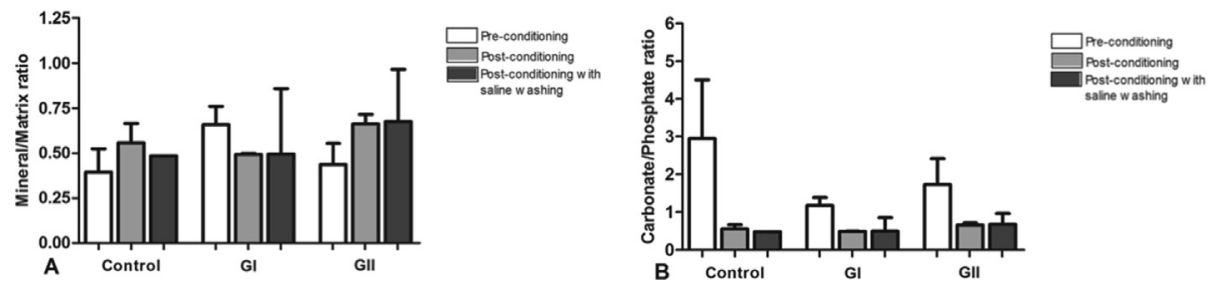

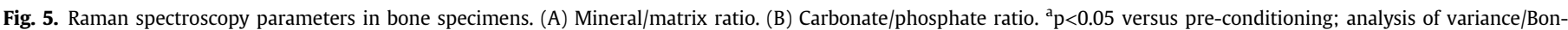
ferroni test. GI, group I. GII, group II.

Table 3

Mean Knoop microhardness according to teeth analyzed regions.

\begin{tabular}{|c|c|c|c|c|c|c|}
\hline & Control PRE & Control POST & Group I PRE & Group I POST & Group II PRE & Group II POST \\
\hline \multicolumn{7}{|l|}{$0.01 \mu \mathrm{m}$ (Superficial) } \\
\hline Mean & 34.08 & 40.25 & 38.48 & 24.06 & 38.48 & 32.96 \\
\hline Standard error of the mean & 5.994 & 9.369 & 4.411 & 1.413 & 4.411 & 2.733 \\
\hline \multicolumn{7}{|l|}{$0.11 \mu \mathrm{m}($ Medium $)$} \\
\hline Mean & 29.75 & 35.72 & 33 & 37.69 & 40.12 & 39.23 \\
\hline Standard error of the mean & 5.289 & 8.076 & 2.115 & 7.558 & 3.396 & 2.396 \\
\hline \multicolumn{7}{|l|}{$0.21 \mu \mathrm{m}$ (Deep) } \\
\hline Mean & 41.73 & 33.02 & 34.41 & 42.4 & 43.12 & 39.64 \\
\hline Standard error of the mean & 11.52 & 6.281 & 0.6339 & 6.994 & 3.25 & 3.799 \\
\hline
\end{tabular}

Control, control group; Group I, Carnoy's solution with chloroform; Group II, Carnoy's solution without chloroform; PRE, pre-conditioning; POST, post-conditioning. 

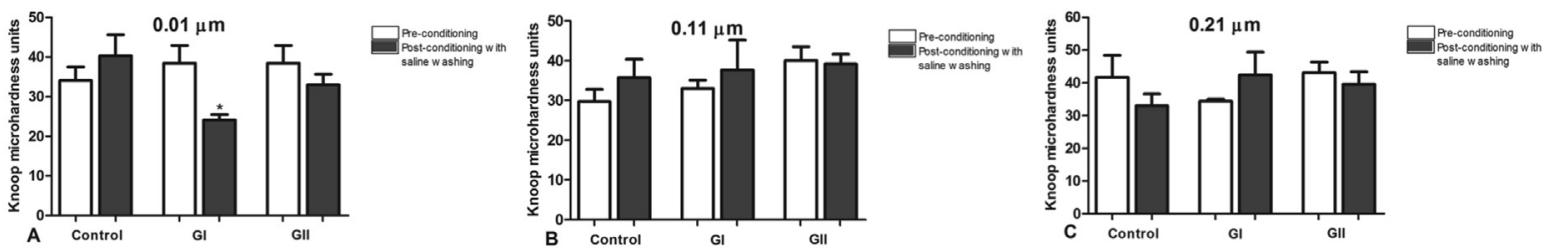

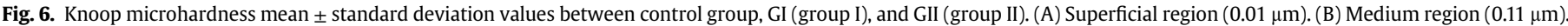
(C) Deep region $(0.21 \mu \mathrm{m}) .{ }^{*} \mathrm{p}<0.05$ versus pre-conditioning; Student $t$ test. GI, group I. GII, group II.
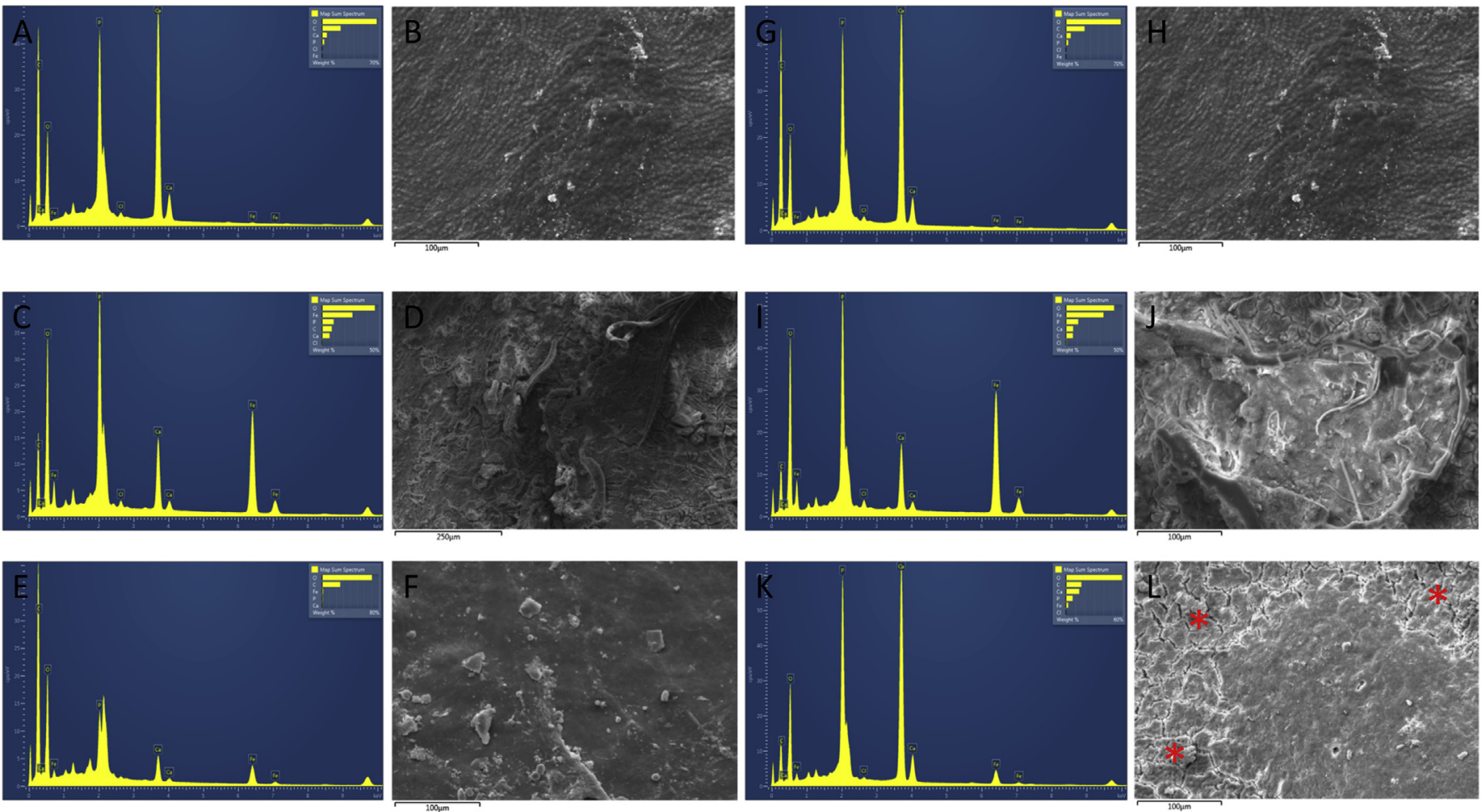

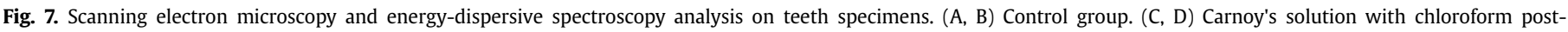

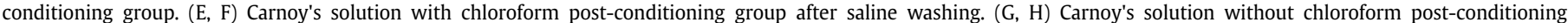
group. (I, J) Carnoy's solution without chloroform post-conditioning group after saline washing. Cementum microcracks were observed $\left({ }^{*}\right)$.

eroded appearance was found on the surface treated with Carnoy's solution without chloroform (Fig. 7J).

In bone, similarly to cementum, the physiological amount of Ca is usually greater than the level of P (Almehdi et al., 2013), as observed in Fig. 8A. Group I showed a reduced and inverted $\mathrm{Ca}-\mathrm{P}$ ratio, and the increase of organic component (C) and Fe concentration (Fig. 8C). Post-conditioning with saline washing rendered the abnormal $\mathrm{Ca}-\mathrm{P}$ ratio but with inverted proportions between both chemical contents, increased organic component (C), and reduction of Fe concentration (Fig. 8E). Group II showed a slight inversion of the $\mathrm{Ca}-\mathrm{P}$ ratio and an increase in the organic component (C) content; however, there was a highlighted increase in $\mathrm{Fe}$ concentration (Fig. 8I). Post-conditioning with saline washing rendered a normal $\mathrm{Ca}-\mathrm{P}$ ratio, a highlighted increase of the organic component (C), and reduction of Fe concentration (Fig. 8I). The smear-layer was observed in both groups (Fig. 8D and H); however, it was intense in group II (Fig. $8 \mathrm{H}$ ). Post-conditioning with saline washing did not show its presence (Fig. $8 \mathrm{~F}$ and J), but an evident eroded surface aspect was observed in group II after saline washing (Fig. 8J).

\section{Discussion}

The ideal management of aggressive jaw lesions, especially benign odontogenic tumors, has been widely discussed in the literature. The treatment would be able to provide complete lesional exeresis without significant post-operative morbidity (Costa et al., 2010; Pogrel, 2015). In this context, Carnoy's solution has been considered an effective adjunct therapy (Albuquerque et al., 2016), and data regarding this treatment have been reported usually based on in vivo studies. For example, a systematic review with a meta-analysis showed that Carnoy's solution combined with enucleation resulted in the lowest recurrence rate (Al-Moraissi et al., 2017). Thus, such clinical evidence reinforces the importance of the present investigation, since in vitro Carnoy's solution data have not yet been published. To date, this is the first in vitro study using both Carnoy's formulations for which there are reported data from Raman microspectroscopy, scanning electron microscopy with energy dispersive spectroscopy, and microhardness of human tooth and bone specimens. 

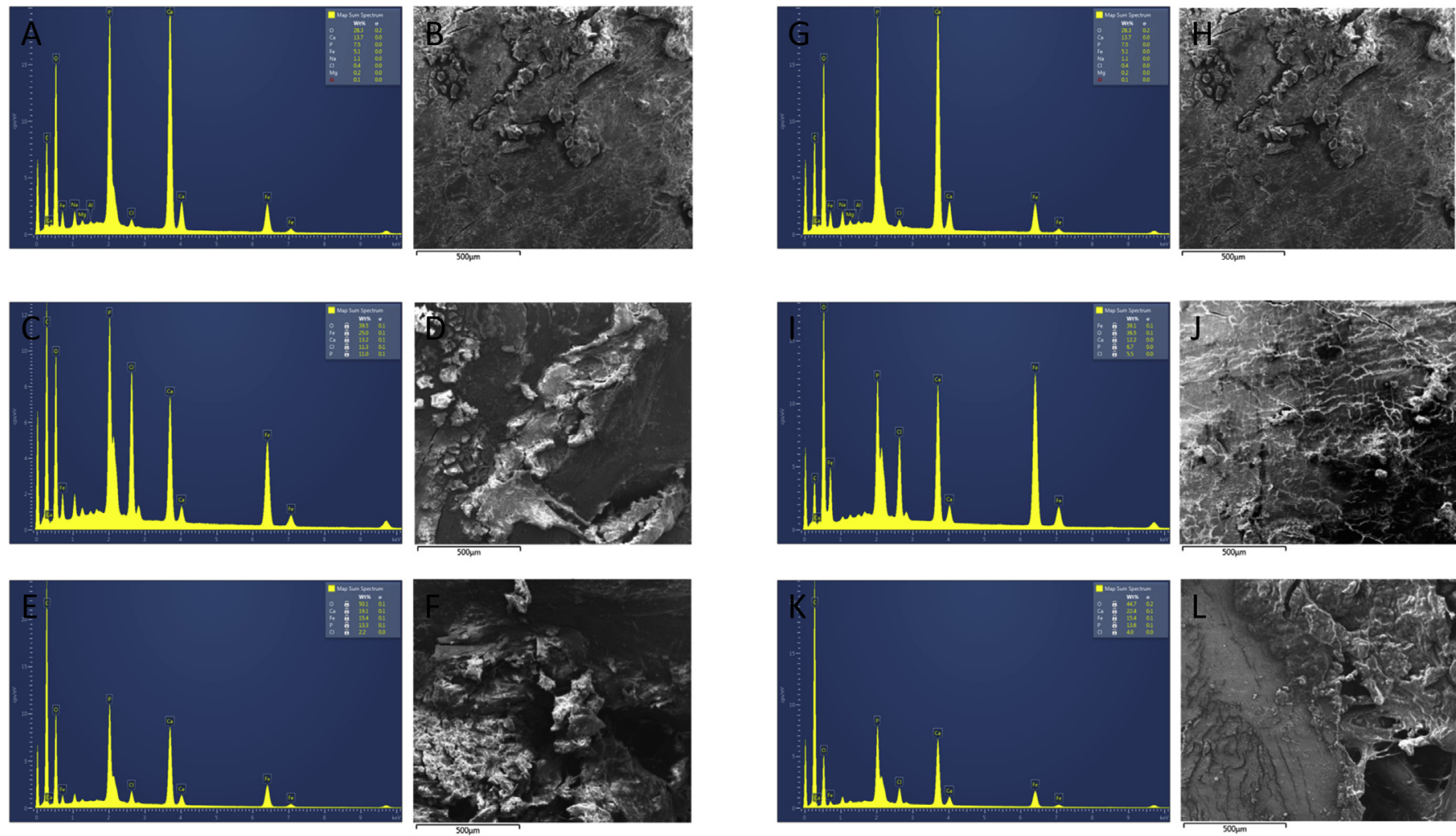

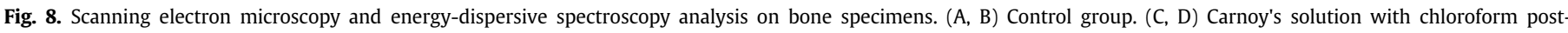

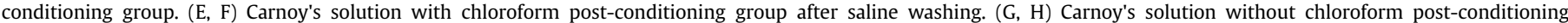
group. (I, J) Carnoy's solution without chloroform post-conditioning group after saline washing.

The analysis of chloroform influence on Carnoy's solution properties when applied to oral hard tissues was an important aspect addressed in the current literature. Data from this study showed some chemical, physical, and ultrastructural differences in specimens subjected to Carnoy's solution with chloroform. Hellstein et al. (2007) evaluated the tissue damage after using Carnoy's solution in specimens containing bone, connective tissue, and mucosa, and they did not observe a chloroform-related additional tissue effect. However, a clinical study (Dashow et al., 2013) showed a beneficial effect of formulations using chloroform on the rate of recurrence of odontogenic keratocyst, which significantly reduced the rate and the average time of recurrence in comparison with Carnoy's solution without chloroform. In the present in vitro study, the presence of chloroform resulted in more destruction and structural alterations of human mineral components.

Bone tissue (Abou Neel et al., 2016) and dentin and cementum (Schulze et al., 2004) have both organic and inorganic contents. The inorganic component of these hard tissues consists of biological apatite $\left(\mathrm{Ca}_{10}\left(\mathrm{PO}_{4}\right) 6(\mathrm{OH})_{2}\right)$, which possesses a hexagonal unit cell (Abou Neel et al., 2016). Repetitions of biological apatite unit cells produce crystals of various sizes with calcium-phosphate ratio differences (Almehdi et al., 2013), which provides the necessary hardness (Abou Neel et al., 2016). In this study, Raman spectra analysis of bands and peaks showed alterations in phosphate v1 $\left(\sim 960 \mathrm{~cm}^{-1}\right)$, which was characterized by the loss of the phosphate $\mathrm{v} 1$ band in both groups on the dental/bone specimens. Scanning electron microscopy with energy dispersive spectroscopy showed that Carnoy's solution altered the proportion between the elemental atomic percentage values of $\mathrm{Ca}$ and $\mathrm{P}$, as well as the Knoop microhardness (Gong et al., 2013).

Both $\mathrm{Ca}$ and $\mathrm{P}$ have shown great importance in the composition of bones and teeth, influencing the stiffness and flexibility of these tissues (Abou Neel et al., 2016). Structural modifications can occur, for example, by replacing calcium ions with magnesium and sodium ions, which replaces the hydroxyl sites with fluorides and chlorides, as well as by substituting both phosphate and hydroxyl contents by carbonates. With the substitution of ions, a considerable variation in the properties of the hydroxyapatite can occur; for example, like the substitution of magnesium inhibits the growth of the crystals, substitution by carbonate increases the solubility, whereas the substitution by fluoride decreases the solubility (Nanci, 2008). Considering that these changes reflect on the properties of the related tissues (Abou Neel et al., 2016; Nanci, 2008), the present study highlighted some alterations after microhardness analysis. Carnoy's solution with chloroform showed the highest reduction in the microhardness value, presenting a statistically significant difference, which reinforced the tissue erosion pattern observed in tissues subjected to Carnoy's solution with chloroform. The authors of the present study believe that this finding can be partially explained by the chloroform chemical properties, which enhance the penetration of alcohol in the tissues, promoting tissue dehydration through the dissolution of membrane lipids, and leading to a significant specimen demineralization and tissue damage (Luz et al., 2008; Dias et al., 2016; Tsai, 2006).

Regarding the present study, Raman microspectroscopy was a valuable tool to adequately reflect the chemical patterns of the studied tissues. The known Raman spectrum aspects that define specific cell findings (Kann et al., 2015) were evaluated according to the regions of interest (fingerprint region, $<1800 \mathrm{~cm}^{-1}$; silent region between 1800 and $2800 \mathrm{~cm}^{-1}$; and high-frequency region, $>2800 \mathrm{~cm}^{-1}$ ) (Kong et al., 2015). Several studies have been conducted evaluating calcified human substrates through Raman spectroscopy (Gong et al., 2013; Schulze et al., 2004; Ho et al., 2009; Morris and Mandair, 2011; Seredin et al., 2015); however, there are 
no analyses testing different Carnoy's solution formulations similar to that performed in the present in vitro investigation. In order to evaluate these tissues, isolated peaks of phosphate and carbonate were analyzed; however, the possibility of influence from specific factors (mirroring, size of the evaluated granules, refractive index, and roughness of the specimen) justified the establishment of a relation between peak intensities used in the present methodology (Gong et al., 2013; Morris and Mandair, 2011).

The Carnoy's solutions caused an acidic environment (Nouri et al. 2015; Baker, 1958) that promoted a demineralization process, resulting in the loss of mineral content in both the teeth and bone specimens studied. It is possible that Carnoy's solution-related hydroxyapatite degradation may have occurred as the same way as during physiological processes or pathological conditions, such as bone remodeling and carious lesions. It has been assumed that $\mathrm{pH}$ reduction favors the degradation of the hydroxyapatite in orthocalcium phosphate and di-calcium phosphate dihydrate, whereas a $\mathrm{pH}$ increase enhances the displacement of this chemical reaction to the opposite side, favoring the formation of hydroxyapatite (Abou Neel et al., 2016; Seredin et al., 2015). In addition, the acid pattern related to the Carnoy's solutions also gives a greater propensity to calcium loss, resulting in a more carbonated structure (Abou Neel et al., 2016; Seredin et al., 2015). This finding was evident in the teeth specimens in this study, which showed a mineral matrix/ organic matrix ratio decrease and a carbonate/phosphate ratio increase. This fact was also observed by scanning electron microscopy associated with a dispersive energy spectrometer.

Three-dimensional aspects of the morphological and organizational characteristics of teeth and bone specimens treated with different Carnoy's solutions with chloroform highlighted a significant structural destruction along with an altered $\mathrm{Ca}-\mathrm{P}$ ratio, both occurring in post-conditioning and post-conditioning followed by saline washing. Regarding the solution without chloroform, there was an important structural disorganization of the organic component and a slightly altered mineral content, which was confirmed by energy-dispersive X-ray spectroscopy. Similar findings related to an inverted $\mathrm{Ca}-\mathrm{P}$ ratio and superficial erosion may be observed in a phosphoric acid challenge-based in vitro study performed by Abou Neel et al. (Abou Neel et al., 2016). In addition, these alterations correlated with the Raman microspectroscopy findings.

Carnoy's solution with or without chloroform caused an increase of Fe concentration in all analyzed specimens. This finding probably occurred because of the possibility of a Ca substitution in the stoichiometric formula of the hydroxyapatite by a metal cation (Abou Neel et al., 2016), such as the Fe ion. It has been known that ferric chloride has an acidic pattern and acts by promoting protein coagulation (Nouri et al., 2015). Since Carnoy's solution showed an effect of increased Fe concentration, it is possible that a progressive substitution of Ca by Fe occurred in teeth and bone hydroxyapatite crystals, increasing the Fe tissue concentration. As Carnoy's solution containing chloroform showed the highest Fe concentration, then a more pronounced coagulative necrosis may be expected. This hypothesis could justify the satisfactory clinical outcome after using Carnoy's solution with chloroform in comparison to Carnoy's solution without chloroform in its formula (Dashow et al., 2013, 2015).

\section{Conclusion}

Data from this in vitro study showed that Carnoy's solution with or without chloroform demineralized bone and dental tissues, changing their mineral and organic matrix compositions. The presence of chloroform rendered a highlighted structural superficial damage in comparison with the Carnoy's solution without this chemical agent. In addition, mean hardness values were altered after using either Carnoy's solution with or without chloroform. Although clinical practitioners have widely used both Carnoy's solutions as an adjunct therapy in benign aggressive jaw lesions, further in vitro and animal studies are still necessary in order to expand our knowledge about Carnoy's formulations containing or not containing chloroform.

\section{Conflict of interest and/or financial support} None.

\section{References}

Abou Neel EA, Aljabo A, Strange A, Ibrahim S, Coathup M, Young AM, et al: Demineralization-remineralization dynamics in teeth and bone. Int J Nanomedicine 11: 4743-4763, 2016

Al-Moraissi EA, Dahan AA, Alwadeai MS, Oginni FO, Al-Jamali JM, Alkhutari AS, et al: What surgical treatment has the lowest recurrence rate following the management of keratocystic odontogenic tumor? A large systematic review and meta-analysis. J Craniomaxillofac Surg 45(1): 131-144, 2017

Albuquerque AFM, Silva PGB, Bezerra TMM, Alves APNN, Pereira KMA, Ribeiro TR, et al: Surgical treatment with or without the use of Carnoy solution in aggressive tumors of odontogenic origin: a systematized critical literature review. Int J Clin Dent 9(2): 87-98, 2016

Almehdi A, Aoki A, Ichinose S, Taniguchi Y, Sasaki KM, Ejiri K, et al: Histological and SEM analysis of root cementum following irradiation with Er:YAG and CO2 lasers. Lasers Med Sci 28(1): 203-213, 2013

Baker JR: Principles of biological microtechnique; a study of fixation and dyeing. London: Methuen, 1958

Butler HJ, Ashton L, Bird B, Cinque G, Curtis K, Dorney J, et al: Using Raman spectroscopy to characterize biological materials. Nat Protoc 11(4): 664-687, 2016

Cano J, Benito DM, Montans J, Rodriguez-Vazquez JF, Campo J, Colmenero C: Glandular odontogenic cyst: two high-risk cases treated with conservative approaches. J Craniomaxillofac Surg 40(5): e131-e136, 2012

Carvalho FSR, Feitosa VP, Fonseca SGC, Araújo TDV, Soares ECS, Fonteles CSR, et al: Physicochemical and rheological characterization of different Carnoy's solutions applied in oral and maxillofacial surgery. J Raman Spectrosc 48: 1375-1384, 2017

Costa FWG, Brito GAC, Pessoa RMA, Soares ECS: Histomorphometric assessment of bone necrosis produced by two cryosurgery protocols using liquid nitrogen: an experimental study on rat femurs. J Appl Oral Sci 19(6): 604-609, 2011

Costa FWG, Soares ECS, Batista SHB: Cryosurgery in treatment of benign jaw lesions: literature review and analyze of 103 cases previously reported. RSBO 7(2): 208-215, 2010

Cutler EC, Zollinger R: The use of sclerosing solutions in the treatment of cysts and fistulae. Am J Surg 19(3): 411-418, 1933

Dashow J, Helman JI, Edwards SP, McHugh J, Ward BB: Keratocystic odontogenic tumor recurrence rates with enucleation and curettage using Carnoy's versus modified Carnoy's solution. J Oral Maxillofac Surg 71(9): e4-5, 2013

Dashow JE, McHugh JB, Braun TM, Edwards SP, Helman JI, Ward BB: Significantly decreased recurrence rates in keratocystic odontogenic tumor with simple enucleation and curettage using Carnoy's versus modified Carnoy's solution. J Oral Maxillofac Surg 73(11): 2132-2135, 2015

Dias AR, Pereira MA, Mello ES, Zilberstein B, Cecconello I, Ribeiro Junior U: Carnoy's solution increases the number of examined lymph nodes following gastrectomy for adenocarcinoma: a randomized trial. Gastric Cancer 19(1): 136-142, 2016

Ecker J, Horst RT, Koslovsky D: Current role of Carnoy's solution in treating keratocystic odontogenic tumors. J Oral Maxillofac Surg 74(2): 278-282, 2016

Gong B, Oest ME, Mann KA, Damron TA, Morris MD: Raman spectroscopy demonstrates prolonged alteration of bone chemical composition following extremity localized irradiation. Bone 57(1): 252-258, 2013

Gurol M, Uckan S, Guler N, Yatmaz PI: Surgical and reconstructive treatment of a large ossifying fibroma of the mandible in a retrognathic patient. J Oral Maxillofac Surg 59(9): 1097-1100, 2001

Hawkins C, Sterrett JD, Russell C: Citric acid demineralization of cementum and dentin: the effect of the storage medium. J Clin Periodontol 24(4): 264-271, 1997

Hellstein J, Hopkins T, Morgan T: The history and mystery of Carnoy solution: an assessment of the need for chloroform. Oral Surg Oral Med Oral Pathol Oral Radiol Oral Endod 103(4): 24, 2007

Ho SP, Senkyrikova P, Marshall GW, Yun W, Wang Y, Karan K, et al: Structure, chemical composition and mechanical properties of coronal cementum in human deciduous molars. Dent Mater 25(10): 1195-1204, 2009

Kann B, Offerhaus HL, Windbergs M, Otto C: Raman microscopy for cellular investigations-from single cell imaging to drug carrier uptake visualization. Adv Drug Deliv Rev 89: 71-90, 2015

Kong K, Kendall C, Stone N, Notingher I: Raman spectroscopy for medical diagnostics-from in-vitro biofluid assays to in-vivo cancer detection. Adv Drug Deliv Rev 89: 121-134, 2015

Lee PK, Samman N, Ng IO: Unicystic ameloblastoma-use of Carnoy's solution after enucleation. Int J Oral Maxillofac Surg 33(3): 263-267, 2004 
Luz DA, Ribeiro Jr U, Chassot C, Collet ESFS, Cecconello I, Corbett CE: Carnoy's solution enhances lymph node detection: an anatomical dissection study in cadavers. Histopathology 53(6): 740-742, 2008

Morris MD, Mandair GS: Raman assessment of bone quality. Clin Orthop Relat Res 469(8): 2160-2169, 2011

Nanci A: Ten Cate's oral histology: development, structure, and function. Maryland heights. MO: Mosby, 2008

Nouri S, Sharif MR, Sahba S: The effect of ferric chloride on superficial bleeding. Trauma Mon 20(1): e18042, 2015

Owosho AA, Bilodeau EA, Vu J, Summersgill KF: Orofacial dermal fillers: foreign body reactions, histopathologic features, and spectrometric studies. Oral Surg Oral Med Oral Pathol Oral Radiol 117(5): 617-625, 2014

Pogrel MA: The keratocystic odontogenic tumour (KCOT)-an odyssey. Int J Oral Maxillofac Surg 44(12): 1565-1568, 2015

Pollan LD, Kruger GO, Reynolds DC, Mopsik ER: Osseous cryosurgery and its effect on adjacent pulpal tissues. Oral Surg Oral Med Oral Pathol 38(5): $668-674,1974$

Rajeshkumar BP, Rai KK, Geetha NT, Shivakumar HR, Upasi AP: Carnoy's in aggressive lesions: our experience. J Oral Maxillofac Surg 12(1): 42-47, 2013
Schulze KA, Balooch M, Balooch G, Marshall GW, Marshall SJ: Micro-Raman spectroscopic investigation of dental calcified tissues. J Biomed Mater Res A 69(2): 286-293, 2004

Seredin P, Goloshchapov D, Prutskij T, Ippolitov Y: Phase transformations in a human tooth tissue at the initial stage of caries. PLoS One 10(4), 2015 e0124008

Suvorova EI, Petrenko PP, Buffat PA: Scanning and transmission electron microscopy for evaluation of order/disorder in bone structure. Scanning 29(4): 162-170 2007

Tsai C-J: Comparing DNA damage caused by formaldehyde, glutaraldehye, Carnoy's and methacarn in cancer tissue fixations. Bowling Green State University, 2006

US Food and Drug Administration: Section 460.200. In: FDA compliance policy guides. Washington, DC: Food and Drug Administration, 219, 1992

Voorsmit RA, Stoelinga PJ, van Haelst UJ: The management of keratocysts. J Maxillofac Surg 9(4): 228-236, 1981

Voorsmit RA: The incredible keratocyst: a new approach to treatment. Deutsch Zahnarztl Z 40(6): 641-644, 1985

Zizzari VL, Zara S, Tetè G, Vinci R, Gherlone E, Cataldi A: Biologic and clinical aspects of integration of different bone substitutes in oral surgery: a literature review. Oral Surg Oral Med Oral Pathol Oral Radiol 122(4): 392-402, 2016 